\title{
Estrategias Transmedia y enunciación desde los márgenes: El universo narrativo de The Undocumented, Marco Williams, 2013
}

\section{Transmedia strategies and enunciation from the margins: The narrative universe of The Undocumented, Marco Williams, 2013}

Dr. Roberto Arnau Roselló Grupo de Investigación ITACA

(Universitat Jaume I)

\section{Fecha de recepción: 10 de octubre de 2015}

Fecha de revisión: 7 de enero de 2015

Para citar este artículo: Arnau Roselló, R. (2016): Estrategias Transmedia y enunciación desde los márgenes: El universo narrativo de The Undocumented, Marco Williams, 2013, Icono 14, volumen (14), pp. 233-257. doi: 10.7195/ri14.v14i1.931 


\section{Resumen}

El auge de las narrativas no lineales multimedia ha propiciado un aumento exponencial de la producción de contenidos audiovisuales que exploran las potencialidades discursivas asociadas al tipo de consumo visual contemporáneo caracterizado por la reticularidad y conectividad del medio, la transmedialidad, la posibilidad de interacción, de geolocalización, de navegación, la movilidad de las pantallas, la atomización de las audiencias o la fragmentación del relato. En este contexto multiforme, se abre un espacio para ciertos proyectos independientes de carácter transmediático que despliegan sus propuestas significantes como un modo de poner en cuestión los mecanismos propios de la representación, de llevar más allá de la referencialidad discursiva sus creaciones, de proponer un marco interpretativo alternativo al hegemónico desde el que el interactor pueda construir su propia interpretación del universo narrativo. En este caso, nos detendremos en el estudio y análisis del proyecto The undocumented (Marco Williams, 2013), cuya estrategia discursiva principal estriba en la triple materialización del producto: un documental cinematográfico transmedia que complementa la narración filmica con una aplicación interactiva multimedia on line, The map of the undocumented, y el videojuego crítico The migrant trail.

\section{Palabras clave}

Cine documental - Transmedia - Gameplay ética - Hipertexto - Política

\section{Abstract}

The rise of non-linear multimedia narrative has led to an exponential increase in the production of audiovisual contents exploring the discursive potential associated with the kind of contemporary visual consumption characterized by reticularity and media connectivity, transmediality, the possibility of interaction, geolocation, navigation, screens mobility, the fragmentation of audiences and the non-linear storytelling. In this multiform context, a space has been open for certain independent transmedia projects who display their significant proposals as a way of questioning the mechanisms of representation, to carry beyond the discourse referentiality their creations, to propose an alternative framework to the hegemonic interpretation 
from which the interactor can build his own interpretation of the narrative universe. In this case, we will stop in the study and analysis of the project The undocumented (Marco Williams, 2013), whose main discursive strategy lies in the realization of the triple product: a transmedia documentary film supplementing the film narrative with an interactive multimedia application on line, The map of the undocumented, and critical videogame The migrant trail.

\section{Key Words}

Documentary film - Transmedia - Gameplay ethics, hypertext - Politics

\section{Introducción y reflexiones de base: contextos de recepción y producción Transmedia en la era digital}

La evolución y progresiva implantación de las narraciones transmedia en el panorama audiovisual del nuevo milenio ha supuesto un punto de inflexión en las concepciones sobre la distribución, el diseño y las potencialidades significantes de los productos audiovisuales. La diversificación de canales, soportes y plataformas en los que se materializan estas narraciones, asociada a la performatividad de sus potenciales usuarios, supone un campo de investigación tan amplio que es necesario concretar en el análisis de algunos productos particulares los rasgos de determinadas propuestas innovadoras para establecer conclusiones ajustadas a un objeto definido.

En el ámbito hipermorfo del videojuego se han generado proyectos originales en cuyo carácter confluyen diversas tendencias estéticas procedentes de ámbitos como el arte digital, el cine y la fotografía documental, el diseño, la ilustración y la crítica social. El desarrollo de plataformas y aplicaciones de contenido crítico está viviendo un momento de esplendor creativo sin precedentes, dada la combinación de circunstancias diversas que han favorecido la cristalización de una tendencia particular, basada en la crítica sociopolítica a través de herramientas videolúdicas específicas, desarrolladas por programadores independientes al calor del poder expansivo de internet y del desarrollo paulatino de un determinado modelo de jugador crítico.

DOI: ri14.v14i1.931 | ISSN: 1697-8293 | Año 2016 Volumen 14 N 1 | ICONO14 


\section{MONOGRÁFICO}

Para adentrarnos, pues, con ciertas garantías en descripciones conceptuales, que transitan por terrenos de naturaleza resbaladiza, hemos de iniciar nuestra argumentación realizando una serie de matizaciones relevantes en cuanto al uso de determinados conceptos que conforman el título de este trabajo. Trataremos de despejar las múltiples incógnitas que se suscitan en torno a los ejes teóricos fundamentales que abordamos.

Respecto al primero de los ejes, es necesario señalar que el laberinto terminológico que se ha generado entorno a las prácticas Transmedia nos aboca a una confusión conceptual de partida, generada por la enorme cantidad de conceptos usados para referirse a ellas. Términos como cross media, intermedia, narrativa aumentada, synergetics storyworlds, multimodalidad, multimedialidad, inmersividad, multiplataforma, y muchos otros, se han asociado, de manera desigual, a estas prácticas en el nuevo contexto comunicativo global. Cada uno de ellos, por su parte, destaca un aspecto concreto de este tipo de narraciones y trata de referirse a una misma experiencia esencial: la de una práctica interpretativa de producción de sentido basada en historias que se expresan a través de una combinación de lenguajes, medios y plataformas (Scolari, 2013: 25).

Sin embargo, a pesar de esta dispersión terminológica, es un hecho contrastable que el concepto Transmedia y, en concreto, el conocido como Transmedia storytelling, se ha convertido en uno de los principales ejes de la investigación comunicativa por cuanto relaciona medios anteriormente dispersos en enunciados complejos y organiza narraciones multimodales que se diversifican en distintos soportes. Esta capacidad para aglutinar entorno a un término la cualidad de crear relatos mas allá del formato específico en el que fueron concebidos y transformar las narraciones en piezas de un macro-relato o universo narrativo expandido, lo convierten en una idea de alcance teórico destacable que ha emergido (y se ha puesto de moda, dicho sea de paso) en esta última década gracias a las investigaciones de diversos autores.

Henry Jenkins, del Massachusetts Institute of Technology, acuña inicialmente el concepto para referirse a aquellas estructuras narrativas diseñadas para fomentar la convergencia entre los distintos medios que canalizan las diversas formas de 
expresión de nuestra cultura (Jenkins, 2003). Transmedia sería, según Jenkins, el eje en torno al que se vertebra toda una corriente de producción de contenidos que se fundamenta en la construcción de relatos que fluctúan entre diversos espacios de significación. Este flujo canaliza la experiencia narrativa del usuario (ahora prosumer) a través de diferentes formatos que fomentan su implicación en el ulterior desarrollo e interpretación del relato. A raíz del impacto científico e industrial del concepto, otras investigaciones abordarán su estudio aportando nuevos puntos de vista al objeto.

Entre ellas, las investigaciones pioneras en España realizadas por Scolari proponen una caracterización del relato transmedia atendiendo a múltiples factores. Para él, una narración transmedia debe articularse en torno a cuatro ejes fundamentales que pueden convivir al mismo tiempo (aunque en distinto grado) en un mismo enunciado. En primer lugar, el producto se concibe para ser concretado en varios medios, que aportarán, a su vez, sus potencialidades expresivas específicas al espacio textual en cuestión (ver figura 1). En segundo lugar, se trata de una producción integrada en la que se combinan complementariamente los diferentes soportes del relato. En tercer lugar, su consumo se realiza desde un número considerable de dispositivos digitales diversos como ordenadores, teléfonos móviles, tablets, televisores, etc. Por último, el uso de distintos medios responde a la necesidad discursiva de servir de soporte a las exigencias narrativas de un universo en construcción que depende del tipo de proyecto y formato en que se desarrolle (Scolari, 2013: 57).

Esencialmente, esta caracterización del concepto haría referencia a aquellos objetos textuales que se sitúan más allá del relato fundacional (el origen del discurso) y complementan el sentido del discurso en un espacio (hiper)textual extendido. Este espacio, que Genette denominó paratexto, integra una enorme diversidad de prácticas diegéticas (visuales y no visuales) que suponen ampliaciones potenciales del universo narrativo de una obra, de tal modo que refuerzan y extienden la narración, la completan, la estructuran y perfilan su sentido (Genette, 1997). En este sentido, la idea de transmedia remite a conexiones intertextuales que se remontan muy atrás en la historia de los medios audiovisuales, como demuestra la propia existencia de la cultura mainstream. Las superproducciones cinematográficas que por su impacto cultural han superado con creces el espacio de la pantalla en las 


\section{MONOGRÁFICO}

salas, como Star Wars, Ghostbusters, Jurassic Park, Matrix y otras muchas, ya anticipaban la capacidad de aumentar el espectro discursivo de la obra fílmica para abarcar nuevos horizontes y formatos en historias que podían ser consumidas en soportes muy diversos. No obstante, hay que poner de relieve que el potencial de la narración transmedia no ha eclosionado hasta la implantación de la web $2.0 \mathrm{y}$ ha ido desarrollándose al ritmo creciente del las tecnologías que la hacen posible, de modo que en el caso de las anteriores producciones tendríamos que hablar de objetos transmedia "avant la lettre". En la era de internet, el carácter paratextual de buena parte de las narraciones digitales es consustancial al contexto tecnológico en el que nos movemos.

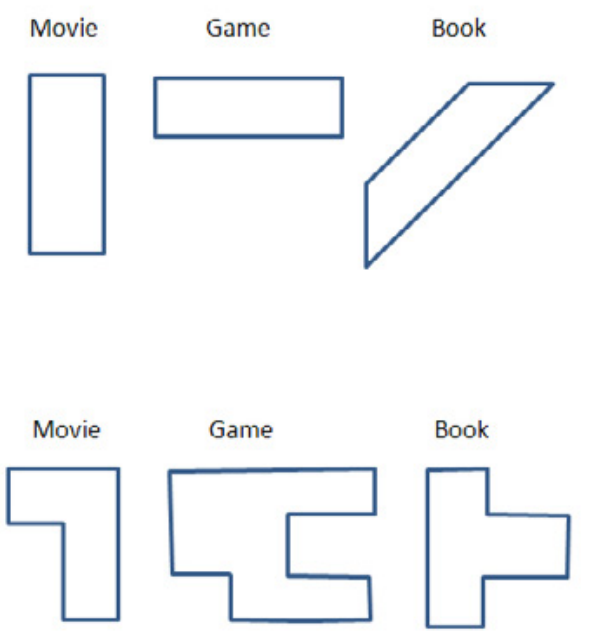

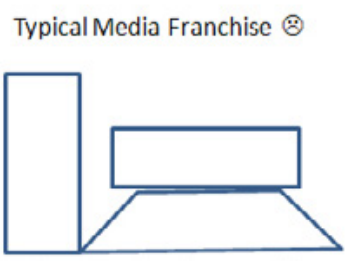

Whole is Less than the sum of the parts: dlssatisfying conclusion to consuming all media

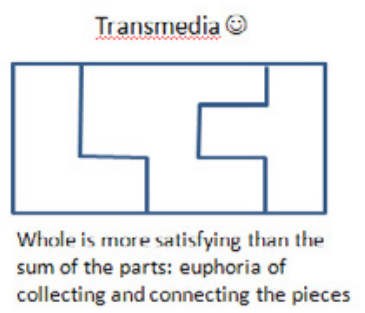

(ㄷ)(1)

Figura 1: Transmedia Storytelling (Robert Pratten)

De otro lado, el papel desencadenante que desempeña la evolución de los dispositivos audiovisuales y los mecanismos tecnológicos en el desarrollo de nuevas subjetividades y modos de expresión a lo largo de la primera década del siglo XXI, aceleran un acontecimiento cognitivo sin precedentes. Sin abandonar las herra- 
mientas retóricas heredadas de los medios tradicionales, estas nuevas narrativas visuales han propiciado también nuevos usos, particularizando así sus capacidades expresivas y significantes. Precisamente, en la actualidad, la rápida evolución tecnológica y expresiva de los enunciados audiovisuales hace que asistamos también al desarrollo y cristalización de un contexto en el que estas transformaciones están generando verdaderas mutaciones en los modos de hacer, de ver, y, en consecuencia, de pensar la imagen. Las tecnologías construyen los objetos hipertextuales que consumimos, al tiempo que modelan nuestra subjetividad, ensanchando los universos discursivos en los que se insertan los ubícuos productos culturales. Estos cambios vertiginosos del contexto de producción-recepción, además de implicar a los usuarios, suponen una prueba de adaptación para las industrias culturales que ven amenazado su modelo tradicional de negocio.

En esta dirección se expresa Scolari (2013) cuando analiza la atomización de las audiencias y el impacto negativo de esta tendencia en la rentabilidad y la estructura del negocio actual de las industrias culturales. Así, las narrativas transmedia se presentan en el actual contexto de redefinición del espacio tecnológico-cultural como una posible solución para afrontar la fragmentación de las audiencias y la dispersión del negocio, dada su capacidad para proponer una experiencia común que abarca diferentes medios y dispositivos unidos por un mismo hilo o discurso narrativo. De este modo se produce una reagrupación de las audiencias en torno a un relato que transita de un extremo al otro del espectro mediático abarcando viejos y nuevos medios, atravesando géneros y expandiendo su propio espacio narrativo. Si antes las audiencias estaban centradas en los medios, ahora lo están en los relatos, lo que implica un cambio sustancial en las estrategias de venta y agrupación de públicos dispersos que implementan las multinacionales de la industria del espectáculo.

\section{Persuasive games, Interactividad y metodología de análisis}

Respecto al segundo eje en el que se sustenta nuestro estudio, destacaremos el tipo particular de videojuego o aplicación interactiva objeto de análisis, con el fin de establecer el marco teórico de referencia para comprender tanto el alcance 
significante de sus propuestas, como el calado político de sus enunciados visuales. Partiendo de que en epígrafes posteriores de este estudio se analiza el videojuego crítico The Migrant Trail, restringimos nuestro análisis a un tipo particular de videojuego o aplicación interactiva en el que se privilegian aspectos que no tienen que ver con el entretenimiento (los denominados Serious games). Más concretamente, en la línea de lo que Ian Bogost denomina Persuasive Games, se trata de videojuegos creados exclusivamente como vehículos de argumentos (casi siempre ideológicos) que pretenden influenciar a los jugadores y fomentan una interrogación dialéctica acerca de procesos y fenómenos del mundo real, pudiendo suscitar reivindicaciones o críticas en contra de la visión fija de las instituciones, gobiernos y corporaciones (Bogost, 2007: 57). Particularmente, aquellos definidos por Gonzalo Frasca, pionero en el estudio y diseño de videojuegos políticos independientes, como vehículo de experiencias de juego con perfil ideológico determinadas por sus propias reglas (Frasca, 2004: 41).

En una tentativa de delimitación del concepto ambiciosa, Michael y Chen amplían el alcance de los Serious Games a "aquellas herramientas de aprendizaje muy poderosas que permiten a los jugadores experimentar, aprender de anteriores errores y adquirir experiencia, de forma segura, en entornos peligrosos, sensibles 0 de alto riesgo" (Michael, Chen, 2006: 29). También Álvarez, que los identifica con aplicaciones informáticas cuyo objetivo es combinar al mismo tiempo aspectos serios tales como la enseñanza, la comunicación, la información u otros, con resortes lúdicos provenientes del videojuego (Álvarez, 2007: 15). En esta misma dirección apuntan otros autores, como los que consideran el "videojuego como un conjunto de experiencias en las que el jugador participa desde una perspectiva muy concreta, la del personaje que él maneja" (Gee, 2008:23).

Otras aproximaciones teóricas describen entornos en los que se asocian valores morales o éticos a los videojuegos. De este modo, el concepto gameplay ética hace referencia a experiencias inducidas por el juego que pueden ser valiosas desde el punto de vista moral, en las que la interacción con el sistema lúdico a través de mecánicas y reglas, requiere por parte del jugador un tipo de reflexión ético/moral que va más allá del simple cálculo de estrategias óptimas para la consecución de un determinado objetivo (Sicart, 2009: 48). Por ello, este tipo de interacción requiere 
una definición de juegos que los considere como objetos con valores asociados a su diseño, en los que se establezca una relación con los jugadores basada en la limitación pre-diseñada de la "agentividad" (las acciones que el jugador/agente pueden llevar a cabo en el marco de las reglas lúdicas, en definitiva, lo que el jugador puede "hacer"), orientada a crear dilemas éticos que sólo pueden ser resueltos aplicando estrategias morales en la experiencia del juego.

De esta manera, la gameplay ética se estructura en base a tres principios básicos entorno a los que gira su específica creación de sentido y su marco referencial, que delimitan el horizonte de la experiencia del jugador en tanto actividad que ocurre en un entorno prediseñado. Estos elementos, primordiales en el proceso de diseño del juego, también pueden ser analizados como variables capitales de su potencial significante. Por un lado, el mundo del juego (gameworld) se erige como el envoltorio semántico del sistema de juego en el que se combinan narración y simulación; por otro lado, las reglas del juego componen la estructura formal del mismo, los límites en los que transcurre; por último las mecánicas constituyen las acciones disponibles para que el jugador interactúe con el estado del juego. A través de estos componentes la gameplay ética se constituye como un proceso hermenéutico de juego en el que el jugador descodifica el sentido de su experiencia lúdica a través de la interpretación ético/moral del mundo del juego.

Respecto al tercero de los ejes en los que se basa este trabajo, cabe referirse a las particularidades del género interactivo para resolver las incógnitas de nuestra ecuación inicial. Las aplicaciones interactivas on line son artefactos comunicativos complejos que albergan muy diversos enunciados en su seno. Su estructura, responde básicamente a un marco hipertextual compuesto por nodos (unidades semánticas que vehiculan un contenido o un concepto), vínculos (elementos que conectan los nodos entre ellos permitiendo la navegación del usuario de uno a otro) y anclas (pequeña parte del nodo a la que se conecta el vínculo), a través del que se manipulan los distintos medios (audio, video, foto, dibujo, etc.). Elementos capaces de conectar muy diversos medios y enunciados. Este marco funciona como una red de piezas interconectadas de información textual en la que la mayor carga de significado recae en la elección del modo de vincular los elementos de la información (Ribas, 2000: 36). De este modo, la estructura del hipertexto rompe con la linealidad y adopta 


\section{MONOGRÁFICO}

diversas formas en función de la elección, la potenciación del papel del lector, la intervención, la inclusión de hipermedia, su propia complejidad estructural y los grados de variación de la trama, lo que supone un planteamiento situado en las antípodas de la teoría literaria aristotélica (Landow, 2005: 271). De alguna manera, el hipertexto hace visible su propia condición discursiva a través de elementos que no están organizados según un orden lógico ni responden a una guía preestablecida de lectura, restringiendo el acto enunciativo a la interacción del usuario, desencadenante de la generación de sentido. Se fuerzan así los límites de la representación referencial para construir el sentido en otro lugar, con otros medios.

Una vez realizado este somero repaso, fundamental para implementar los análisis con cierta solvencia, nos proponemos establecer una metodología para hacer aflorar los planteamientos teóricos que hemos propuesto en los enunciados de los tres objetos clave de esta narración transmedia: el documental cinematográfico The Undocumented, la aplicación interactiva The Map of The Undocumented y el videojuego The Migrant Trail.

Es obvio que un análisis riguroso de los productos audiovisuales interactivos requiere una herramientas específicas que trasciendan las limitaciones de las empleadas para el film tradicional. Pero no es menos cierto que sin estas herramientas clásicas dicho análisis no tendría sentido. El análisis textual del documental no revelará la realidad o irrealidad de los hechos relatados, sino los mecanismos e ideologías a través de los que otorgamos sentido a esa "realidad en imágenes".

En base a este proceso, la metodología que empleamos se concreta en dos vectores paralelos y complementarios. El primero, de corte clásico, se centra en la descripción de los elementos significantes a nivel contexual (condiciones contextuales de producción, distribución y exhibición del film, determinación de un principio ordenador, inscripción en un modelo de representación determinado) y el análisis de los recursos expresivos (composición, fotografía, profílmico, relación imagen/ sonido, composición musical, interpretación) y narrativos (guión, relato, diégesis, narrador, punto de vista y de escucha, enunciación fílmica). El segundo, adaptado a los objetos interactivos, se centra en la relación entre el contenido (unidades de información), la estructura (vinculaciones semánticas y estructurales) y la pre- 
sentación (interface, intermediario), por un lado, y en los tipos y modalidades de interacción (partida, temporal, espacial, testimonial, ramificada, hipertextual, preferencial, sonora, simulada-inmersiva), por otro. Con este esquema, que aporta elementos definitivos para el análisis hipertextual, sabremos cómo se organizan las distintas maneras de navegar en un desarrollo multimodal no lineal o cómo el usuario puede apropiarse en cierta medida de la narración y dejar huella de su presencia en ella.

En base a todo lo anterior, nos encontramos en situación de plantear los objetivos concretos que guían esta investigación en torno a dos ejes fundamentales de estudio. Primero, delimitar conceptualmente el ámbito teórico en el que se sustentan los productos Transmedia y establecer una vinculación con otros conceptos adyacentes que cimentan este trabajo como los de serious games o narraciones interactivas. Segundo, constatar en base al análisis de un corpus de enunciados que la hibridación de formatos y medios construye las bases para una reflexión metalingüística y política, con (y desde) estas nuevas formas audiovisuales, dirigidas a aquellos espectadores dispuestos a sumergirse en experiencias narrativas activas que se extienden casi indefinidamente. Tercero, conceptualizar la narración como una estrategia de creación de sentido con un patrón estructural definido que se sustenta en una arquitectura de los relatos muy precisa, ordenada y planificada que no ha de obedecer necesariamente a los patrones clásicos de la industria audiovisual. Su potencial significante e innovador se condensan en su peculiar capacidad para construir narraciones expansivas que despliegan los múltiples sentidos a través de lenguajes, formatos y medios diferentes, incluyentes, complementarios.

\section{3 . Resultados}

\section{a. Punto de vista y marcas enunciativas en The Undocumented, Marco Williams, 2013}

El film The Undocumented, es un proyecto independiente dirigido por Marco Williams y producido por él mismo y Thomas Peyton en colaboración con Full Frame, Hiptruth productions, el Human Rights Watch Festival e Independent Lens, que se estrenó en el marco del festival Independent Lens en mayo del año 2013. Se trata 
de un trabajo documental que nos acerca a un episodio oculto de la historia fronteriza reciente de los EEUU. En él se narra la historia desconocida de los mas de 2500 inmigrantes fallecidos en los últimos 15 años al intentar cruzar desde México el Desierto de Sonora (Tucson, Arizona) en busca de una vida mejor al otro lado de la frontera, en los EEUU.

Desde 1998, más de 2000 cuerpos y restos esqueléticos de inmigrantes clandestinos han sido encontrados en la zona sur del desierto de Arizona. Estas desapariciones, consecuencia directa de la política de inmigración estadounidense, han permanecido en el olvido dada la incomodidad que generan en las altas esferas políticas norteamericanas y su impacto negativo en la opinión pública internacional. $\mathrm{Su}$ tratamiento fílmico responde, pues, a un posicionamiento político concreto a favor de la memoria de los emigrantes y de la reforma legislativa pendiente en materia de inmigración. La intención del director es construir un documento fílmico que sea una pieza más de las campañas de organizaciones humanitarias para paliar el fenómeno y concienciar de este dramática situación al espectador.

Tras leer un artículo sobre las muertes en el desierto, el cineasta afroamericano originario de Nueva York, se traslada a Tucson (Arizona) en el verano del 2009, donde comienza el rodaje del film con un equipo mínimo de producción compuesto por un operador de cámara (el propio director) y un técnico de sonido directo. La mínima envergadura del proyecto obliga a buscar financiación y apoyos en todos los frentes posibles, de modo que inicialmente se pone en marcha una campaña de crowdfunding a través del sitio web Kickstarter para impulsar la producción y financiar al menos las primeras semanas de rodaje. Poco a poco, a medida que la investigación avanza y el cineasta vislumbra la posibilidad de acabar la película, distintos apoyos se fueron consolidando (PBS, Independent Lens, HRWFF) para que la producción pudiese llevarse a cabo íntegramente.

Desde su concepción y las primeras fases de la preproducción, se trabaja sobre el film como un posible proyecto multiformato que se despliegue en diversos soportes y adopte un carácter polimórfico, en forma de documental tradicional para su exhibición en salas y centros educativos, de aplicación interactiva, y de videojuego. Esta estrategia transmedia, arriesgada en este caso por la falta de financiación que ponía 
en duda la viabilidad integral del proyecto, requiere necesariamente el trabajo de un equipo numeroso de profesionales encargados del desarrollo de las múltiples facetas del producto, al tiempo que una imprescindible precisión y homogeneidad en el aspecto global de los distintos objetos en los que se materializa la narración.

De este modo, el minimalismo inicial del proyecto queda descartado y las distintas facetas del diseño del producto se desarrollan incluso más que el film original. Como en muchos otros casos, la extensión transmediatica de la narración no nace de una planificación rigurosa de la comercialización del producto (transmedia estratégico) sino que se presenta como una expansión narrativa propiciada por las condiciones favorables del contexto mediático (transmedia táctico).

Desde un punto de vista narrativo, para ilustrar el drama de la inmigración la película se estructura en torno a la historia de Marcos Hernández, un inmigrante clandestino indocumentado de origen mexicano que fijó su residencia en Chicago tras cruzar el desierto de Sonora. Marcos trabaja en la ciudad para enviar dinero a su madre en México D.F. que cuida de su hermano enfermo, a la espera de un trasplante de riñón. Pero el motivo principal por el que este personaje emigra a EEUU reside en la búsqueda de su padre desaparecido en el desierto de Sonora al tratar de entrar clandestinamente al país años atrás. Es un personaje que se encuentra inmerso en el perverso bucle de la inmigración ilegal.

Rodado en pleno verano del año 2009 en Arizona, el filme acompaña a Marcos en la búsqueda del rastro de su padre. Durante el transcurso de esta pesquisa, que se transforma poco a poco en una road-movie, colaborarán diversas instancias que van aportando diferentes testimonios para hacer avanzar la narración: las organizaciones humanitarias locales, los agentes de las patrullas fronterizas que luchan para prevenir las muertes de los inmigrantes, los investigadores médicos y forenses, e incluso el Consulado de México que trabaja en la identificación de los cadáveres o los familiares de los fallecidos que se enfrentan la pérdida de un ser querido. A través de sus cuerpos momificados conocemos las historias de seis inmigrantes y la forma en que grupos humanitarios colaboran, buscando pistas entre sus restos para identificarlos y devolverlos a sus seres queridos. Este crisol de personas involucradas en el infierno de la inmigración revela la extensión global de esta injusticia. 


\section{MONOGRÁFICO}

El carácter naturalizador de la puesta en escena responde a una estrategia observacional del director que se acerca desde un punto de vista formal al proceder del cinéma vérité, buscando representar sin intervenciones, a través de la naturalización del discurso fílmico. Aún así, el film no se construye como un diálogo pasivo entre los personajes y el narrador, sino que se revela como un catalizador de una doble búsqueda: la del padre de Marcos y la de representar la situación de los diversos agente implicados en un problema que nos implica a todos como seres humanos.

Esta estructura narrativa responde a un objetivo diegético concreto que se fundamenta en la tensión que origina entre las diferentes subtramas del relato. El largometraje arranca con una secuencia-prólogo demoledora que anuncia el alcance de la experiencia fílmica que vamos a emprender, el funeral como metonimia, como muestra de el parte por el todo, como un destino teleológico que amenaza a cualquier inmigrante y, por extensión, a cualquier persona, a cualquier espectador. La intención del director es meridiana, situar al espectador ante la observación del abismo de la muerte (algo que a todos nos atañe de manera directa) para hacerle reflexionar sobre el destino final de los cross-borders, representando el que podría ser el estadio final de cada una de las historia individuales que se abordan en el film (y todas las documentadas hasta la fecha). De algún modo, comenzar la narración por el final es una especie de mise en abîme que nos coloca ante la inefabilidad de la tragedia, ante una historia que se retroalimenta a través de una puesta formal contundente. La planificación, angulaciones y ambientes generados por la iluminación natural construyen una atmósfera trágica, asfixiante, que acaba por envolver todo el film.

Las acciones que nos muestra el autor a través de su propio punto de vista son directas, crudas, duras, y se nos restituyen como tales, desprovistas de artificios (por ejemplo cuando los agentes fronterizos descubren a algunos indocumentados en el desierto y rescatan algunos a punto de morir, o los forenses indagan en los restos descompuestos e irreconocibles de otros).

Al margen de los procedimientos retóricos inherentes a cualquier discurso audiovisual, si hay una característica que identifica la puesta en escena en esta obra es, sin duda, la sobriedad y la austeridad. Probablemente el equipo reducido de producción 
condiciona este aspecto al tratarse de una producción independiente que no dispone de medios, pero podemos encontrar elementos diversos que explican esta elección estética. Un ejemplo lo tenemos en el hecho de que la motivación del relato proviene de una búsqueda, de una investigación, al margen de artificios visuales y trampantojos.

La investigación, como método con implicaciones científicas, jalona la narración y funciona como elemento dinamizador de la enunciación, como combustible para la máquina narrativa que se alimenta de la expectativas que van surgiendo del propio relato. Por eso, si nos fijamos en la anterior segmentación secuencial, comprobaremos cómo la dialéctica entre exteriores e interiores en el film no es casual, sino que apuntala formalmente el discurso del realizador. Los espacios exteriores parecen estar reservados al trabajo de prospección y ayuda de las patrullas fronterizas, las organizaciones humanitarias y el desierto. Es el espacio que simboliza la amenaza, el riesgo, la acción perniciosa de la intemperie. En los exteriores el inmigrante se pierde, es detenido, muere o es encontrado cuando ya apenas quedan restos orgánicos de él (Figura 3). Cuando esta alternancia se ha repetido en más de una ocasión, cada vez que una secuencia arranca fuera de un espacio cerrado el espectador es capaz de anticiparse y deducir el carácter propio de la misma. No se trata de que la estructura sea monótona, más bien al contrario, el director nos propone un modo de reforzar la idea de una dialéctica entre dos mundos opuestos, pero complementarios. Por su parte, los interiores representan el espacio de la ciencia, de la solidaridad, la identificación, el activismo social y la memoria familiar. Espacios de reconocimiento, sin iluminación artificial, íntimos, en los que podemos detenernos a conocer más profundamente a los personajes o podemos contemplar con detalle la labor y el esfuerzo de los profesionales. De ese modo, se cimienta luna de las bases sobre la que descansa todo el documental: poner al espectador frente al esfuerzo de muchas personas para evitar y/o paliar el drama de unos semejantes y reflexionar sobre el drama de los clandestinos.

A pesar de que el montaje alterna secuencias de las patrullas fronterizas con otras que representan aspectos relacionados con los inmigrantes, el film no plantea un discurso maniqueo, sino que se sumerge en un problema que implica a diferentes grupos de personas, familiares, agentes, forenses o activistas por los derechos humanos. La repetición y abuso de un esquema inverso de identificación-búsqueda 
MONOGRÁFICO

y búsqueda-identificación refuerza el hecho de que se trata de un proceso desencadenado, en cualquier caso, por incógnitas cuya resolución se presenta, de nuevo, como un bucle infinito, una situación retroalimentada por las tensiones y desigualdades que genera el capitalismo salvaje. Resolver esas incógnitas es el trabajo al que se dedican los personajes, tanto el principal como todos los secundarios. Marcos no encuentra a su padre, tal como muestra la película que ocurre con la mayor parte de los desaparecidos en el desierto. La incógnita, en estos casos, es infinita.

Uno de los aspectos más interesante de la narración reside en el uso puntual del sonido que realiza el director. Hay un momento puntual en el que escuchamos la grabación de la voz del 'coyote' (traficante ilegal de personas entre los dos países) a través del teléfono móvil de Marcos explicándole a éste dónde abandonó a su padre. Es uno de los momentos más desesperantes de la película, en el que el plano frontal de Marcos inclinando el móvil hacia la cámara (en una interpelación directa al espectador que borra de un plumazo el efecto de los elementos naturalizadores que pueblan el film) no consigue concretar el espacio fuera de campo abierto por el sonido de la voz. La narración se traslada más allá de la imagen, a un espacio sonoro formalmente indefinido, en el que encaja la falsa tranquilidad y honestidad del testimonio. La crueldad de este fragmento coloca a cualquier espectador con cierta dignidad en una situación violenta, de rechazo instintivo.

Pero el trabajo narrativo en el ámbito sonoro no acaba ahí. Existe un vínculo intersecuencial de marcado carácter metalingüístico que se vehicula a través del sonido con un mecanismo expresivo más propio de la ficción (no entraremos aquí en la cuestión de la representación de la realidad a estas alturas). Esta metatextualidad evidencia la materialidad del texto fílmico en un referencia explícita al propio relato que se cuenta, digamos, desde dentro. En la secuencia que transcurre en la Coalición por los derecho humanos de Arizona, mientras asistimos al trabajo de las activistas, podemos oír la llamada del personaje conductor del film que pide ayuda a esta organización para encontrar a su padre. Este hecho aislado no sería más que una especie de eco entre diferentes agentes narrativos del film que hace referencia a la conexión (muchas veces invisible) entre ellos, incluso al margen de la diégesis. Pero cuando unas secuencias más adelante, ubicados en su casa, vemos en directo el momento de la llamada que antes sólo hemos percibido a través de la 
banda de sonido, la referencia se torna explícita y a no sólo señala a las conexiones entre personajes de la historia, sino que se convierte en una marca enunciativa que busca la quiebra de la identificación del espectador para activar su espíritu crítico frente a las representaciones. Esta estrategia de distanciamiento, termino acuñado por el dramaturgo Bertolt Brecht a principios del siglo pasado, utiliza técnicas diversas para recordar al espectador que está asistiendo a una representación y estimularlo a pensar sobre lo que está viendo. De este modo, a través de la narración bilocada de un mismo instante, el espectador recupera la consciencia y se aleja de la representación para involucrarse 0 , al menos, tomar conciencia de la existencia de esa realidad mediada más allá de la pantalla.

Hemos visto en el análisis como el film nos adentra en la realidad vivida en primera persona por algunos de los protagonistas de las historia, pero hay espacios de significación donde el film no puede llegar. Para eso precisamente se desarrolla la vertiente transmedia del producto (http://www.undocumented.com) y se diseñan tanto la aplicación interactiva The Map of the Undocumented, como el videojuego The Migrant Trail.

\section{b. El universo Transmedia de The Undocumented: The Map of the Undocumented y The Migrant Trail.}

Como apuntábamos más arriba, el análisis de los fenómenos Transmedia es una tarea compleja, dada la convivencia de medios y estrategias de producción de sentido que combinan este tipo de narraciones. Según la representación de la figura 1, la narración Transmedia no se concibe como una simple suma de medios autónomos cuya entidad es menor que la suma de la partes, sino todo lo contario, como un acoplamiento perfecto de varios medios cuya entidad es muy superior a la de la suma de las partes que ofrece mayores gratificaciones a los usuarios.

En el caso que nos ocupa, cada pieza ocupa su lugar en el puzzle aportando con sus herramientas específicas de significación un valor añadido a cada una de las manifestaciones de la obra. Como punto de partida, un documental, como punto de encuentro de la estrategia Transmedia, una página web. Si la intención formal de Marco Williams con el documental era tratar de que el espectador se identificara con los inmigrantes y las personas que les ayudan a través del mecanismo filmico de la observación, de la 
nula intervención del autor, con The Map of the Undocumented la retorica que facilita la identificación espectatorial es llevada a extremos donde el cine no puede llegar. El usuario es situado ante una representación espacial cuyo motivo principal es un mapa como interface general, en la pagina de acceso (home). La posibilidad de manipular el tamaño del mapa y acercarnos a cada una de las cruces negras revela la entidad del problema que se vive en esa frontera, en la que los cadáveres se amontonan a apenas varios kilómetros de algunas de la ciudades más ricas de EEUU, como Phoenix. Se trata de una aplicación-foro, que sirve de base de datos y de punto de intercambio informativo entre personas que buscan a sus familiares y los distintos cuerpos e organismos dedicados a evitar tal drama a ambos lados de la frontera. Como objeto 2.0, permite al usuario introducir datos (previo cotejo) o aportar cualquier tipo de soporte documental para que pase a formar parte del programa y integra los datos en la visualización diseñada como ficha de cada cadáver encontrado sin identificar.

El interface es aparentemente sencillo (Figura 2), a pesar de el volumen de datos que contiene hace inviable una experiencia completa del aplicativo, que está estructurado para responder más a un uso como base de datos, o de fuente de consulta para periodistas, investigadores, cuerpos policiales u organizaciones de ayuda humanitaria. La inmersión del usuario en la aplicación se realiza de inmediato, ya que estas aplicaciones online, como mecanismos abiertos y generativos se relacionan con su entorno a través de los modos de interacción y navegación y, por tanto, exigen una participación por parte del espectador-usuario que excede el acto hermenéutico con el fin de identificar distintas lógicas de documentación de la realidad y nuevos modelos de subjetividad posibles.

Esta aplicación en particular se presenta como un tipo de enunciado digital con raíces en los videojuegos e hipertextos que ofrece sus propias formas o recursos expresivos, que requiere la aportación física del espectador para navegar por el material existente y al permitir tal interacción proporciona al usuario una vía de composición abierta para descubrir su propio recorrido a través de su navegación. A través de la interrelación de datos geográficos, físicos y fotografías de sus pertenencias (si las hay) se compone un perfil individual de cada una de las cruces, que transforman su inicial anonimato en una identidad concreta (Figura 3), restituyendo así la dignidad de cada inmigrante desaparecido. 


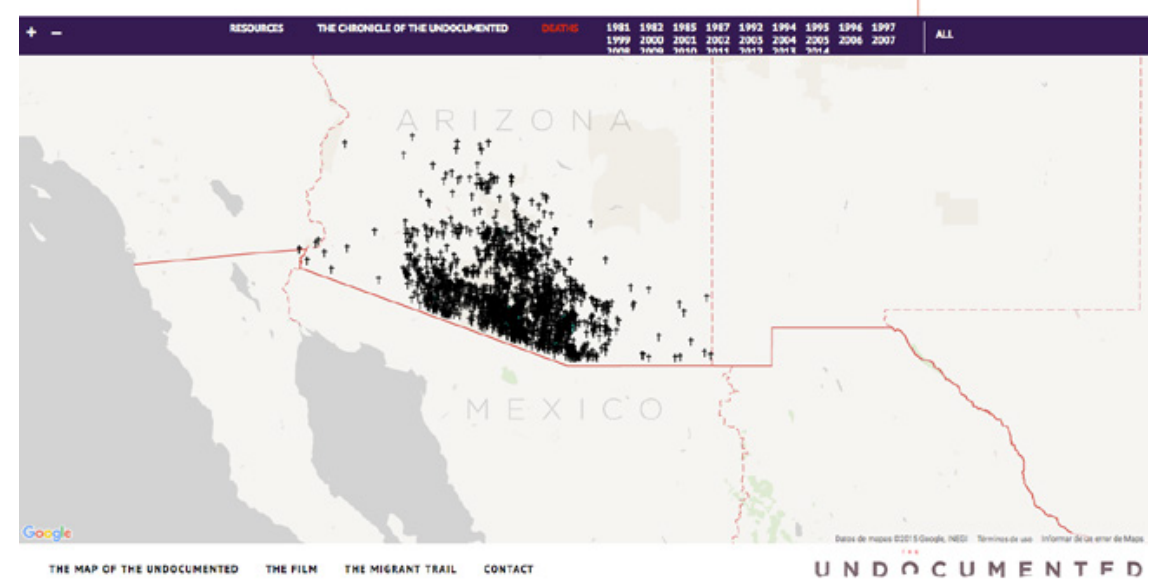

Figura 2: The Map of the Undocumented (Interface principal)

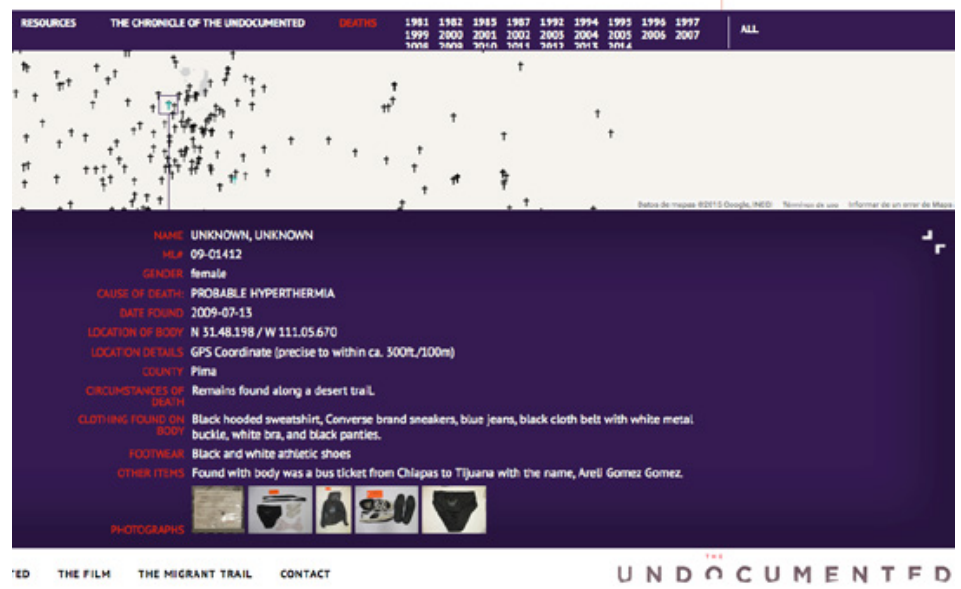

Figura 3: The Map of the Undocumented (detalle identidad)

La reflexión que plantea no es en absoluto inocente: si en el marco político actual los inmigrantes perecen sin ser identificados al atravesar las fronteras, tenemos herramientas que nos permiten hacer visible esa situación, sólo es cuestión de diseñarlas en función de las necesidades concretas de un colectivo en situación precaria. La restitución de la memoria de los desaparecidos es la primera de las prioridades, pero también la construcción de herramientas de ayuda y solidaridad como la propia aplicación, o la reivindicación de una legislación acorde a la envergadura del proble- 


\section{MONOGRÁFICO}

ma. La senda que abre esta iniciativa se concibe como una herramienta para paliar el vacío comunicativo que existe entorno a este tema y extiende el alcance de la narración iniciada en el documental The Undocumented utilizando recursos hipertextuales que amplían el espacio textual inicial de sus enunciados individuales.

Precisamente, en este mismo aspecto incide el videojuego The Migrant Trail, aunque desde una perspectiva distinta y empleando otros mecanismos, más relacionados con la gamificación del universo narrativo propuesto por el documental cinematográfico (Figura 4). El juego supone la culminación del proceso por el cual se refuerza la identificación del usuario con el relato. Para empezar, The Undocumented nos sitúa, en primera persona, frente a las diferentes caras del conflicto mediante los recursos que le son propios (el erróneamente denominado lenguaje cinematográfico), si queremos profundizar The Map of the undocumented organiza su estrategia entorno al potencial semántico y conectivo del hipertexto, y refuerza la identificación del espectador dotando de identidad a los cadáveres anónimos. Para culminar esta escalada hacia la identificación a través de todos los medios, The Migrant Trail propone un viaje (también en primera persona) a través del desierto de Arizona que permite vivir a experiencia a través del mundo jugable de un inmigrante (Figura 5) que nunca puede llegar, o a través del policía de la patrulla fronteriza que siempre gana (Figura 6), con lo que perfila una posible doble identificación con los dos protagonistas principales del relato.

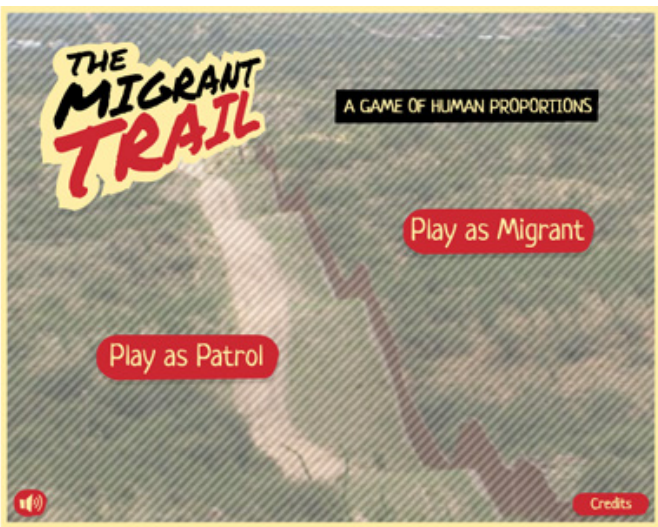

Figura 4: The Migrant Trail (Interface inicial) 
Por si esto fuera poco, es sabido que la capacidad de una aplicación interactiva no es comparable a la de un videojuego. Si queremos que los usuario se adentren en la experiencia directa de un determinado universo narrativo, propongamos un juego y la participación está servida. Las mecánicas del juego, la gameplay, las acciones y las reglas configuran un espacio de significación muy complejo que incita a la participación y sustenta la producción de sentido en lo que el juego "permite hacer" (lo que se ha denominado retórica procedural).

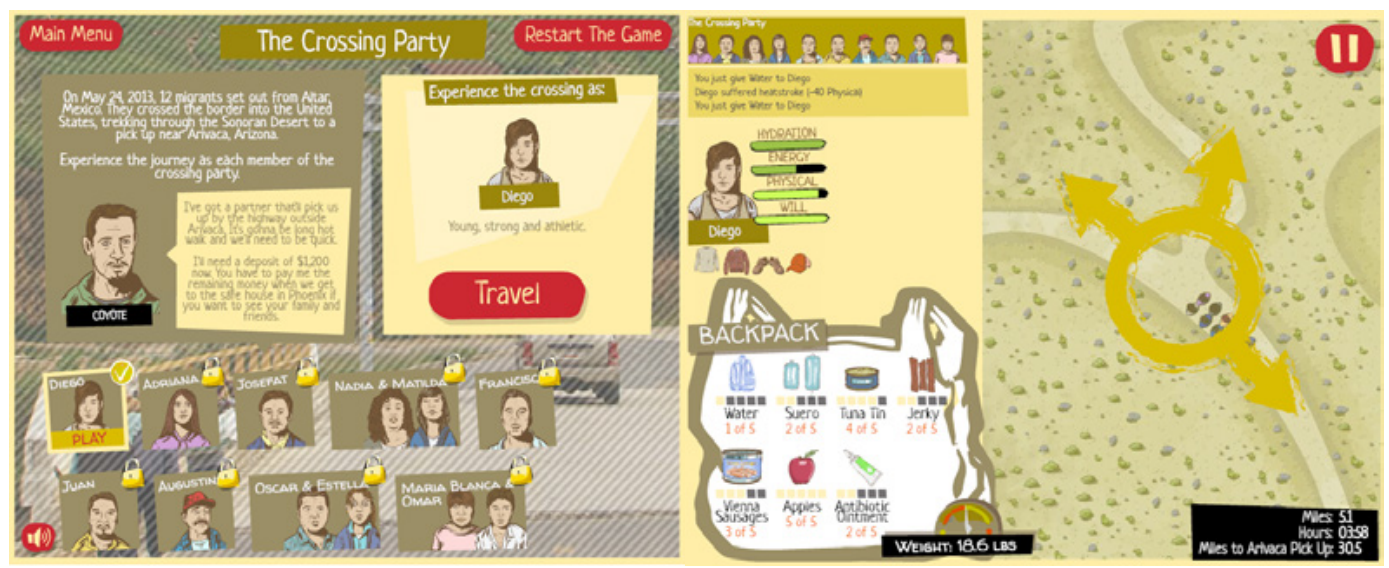

Figura 5: The Migrant Trail (Interface inmigrante)

De este modo, el videojuego despliega una estrategia basada en la crítica sociopolítica a través de herramientas videolúdicas específicas en la que el sentido se construye a partes proporcionales (que no iguales) entre los distintos elementos del juego y el proceso hermenéutico llevado a cabo por el jugador. Es sobre él, en definitiva, donde descansa la responsabilidad acerca de las decisiones adoptadas en el transcurso del juego. Jugando como emigrante es imposible atravesar el desierto, lo cual supone que las reglas definidas por los diseñadores no contemplan el éxito del viaje como un estadio final del juego. El significado es claro, la emigración no es una solución viable, ni deseable para nadie, la desigualdad genera dolor y las víctimas son presa de su propia situación geopolítica. 


\section{MONOGRÁFICO}

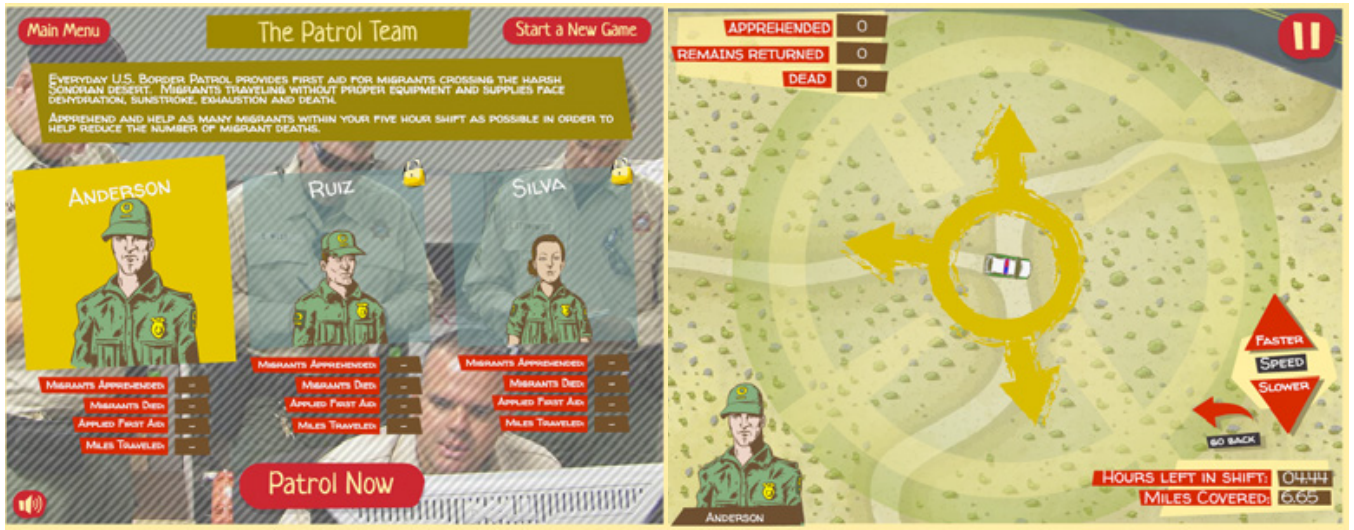

Figura 6: The Migrant Trail (Interface patrulla)

\section{Discusión y conclusiones: el viaje hacia la muti- modalidad narrativa}

Hemos comprobado a través del análisis de los tres productos principales que componen esta narración transmedia cómo el universo diegético lanzado inicialmente desde el cine, se ha concretado y ampliado con el hipertexto y se ha llevado hasta el extremo de la identificación espectatorial con el videojuego. Éste sería uno de los aspectos fundamentales de la aportación de este producto (y este artículo). La canalización de ciertos discursos críticos se ha articulado en torno a este tipo de desarrollos dado su potencial conectivo, intertextual y metarreferencial. La reflexión que se desprende de la interacción de los usuarios con estos productos no sólo se refiere a los contextos sociales representados (en nuestro caso la inmigración), sino que se extiende a los modos de representación de esos contextos, es decir, a la construcción narrativa de esos discursos y a las distintas retóricas propias de cada medio. No cabe duda de que, como texto fílmico, The Undocumented es sumamente interesante, dado que la forma fílmica del relato modela su significado. Pero quizás lo más interesante de este proyecto es, como hemos apuntado desde el principio, la estrategia transmedia que despliega el documental para ampliar sus enunciados visuales. Cada uno de los enunciados narrativo-visuales en los que ha cristalizado la extensión transmedia de la historia, ha construido un acercamiento diferente al objeto, distinguible pero complementario a los demás. Se ha situado 
en un lugar de ese espacio textual donde no se solapa con el resto de medios, ha contribuido como sólo su especificidad le permite y ha ensanchado los límites de una narración que, por la naturaleza de su soporte inicial, resultaba estrecha. Si el documental cinematográfico ha dado sentido al drama de los indocumentados, ha sido de una manera lógica, basada en argumentos (aunque sean visuales, también existe -como no - una retórica de la imagen) que apelan a la verdad; por el contrario, la extensión transmediática del documental ha dado forma a este drama a través de un relato, que no apela a la verdad, en sentido estricto, sino a la verosimilitud, a la interpretación y la participación. La construcción de este cosmos verosímil, interpretable, abierto y multimodal necesita navegantes participativos, prosumidores que lleven la historia mucho mas allá de lo que cualquier story architect hubiera podido imaginar. Ésta es la esencia de la arquitectura Transmedia que hemos analizado en estos enunciados. Estudiados en conjunto, contextualizados (tanto teórica, como históricamente), se nos revelan como un esquema básico que condensa un modelo de creación de sentido cuya arquitectura descansa sobre muy distintos pilares. La estrategia multicanal, sumada a la distribución multiformato ofrece experiencias sígnicas a targets (y niveles) muy diversos, que fluctúan entre narraciones más clásicas y ajustadas a los patrones de consumo tradicionales (como sería el caso del documental cinematográfico), y artefactos videolúdicos elaborados, complejos, cuya corteza hipertextual está compuesta por elementos gráficos, pero también interactivos, jugables, con comportamientos variables, por definición inestables e interpretables.

Lo que nos parece destacable, precisamente, es detectar, en este caso analizado pero también en muchos otros que forman parte del corpus de los productos Transmedia, que la suma de estas capas de distintos lenguajes y medios conforman enunciados cuyo sentido desborda esa suma, en definitiva, que los medios no significan sólo con sus herramientas y técnicas, sino que, al convivir, los diversos medios modelan sus enunciados e indagan en el modo de interconectarse en el seno de un relato expansible hasta encontrar el acople justo para cada caso concreto.

Como universo narrativo, esta experiencia pertenece a un movimiento cultural de intervención sobre la realidad política contemporánea que, sin duda, supone un terreno fértil para la investigación. De hecho, la concreción de determinadas 
estrategias de representación en este producto particular revelan las capacidades significantes de estos enunciados visuales, que han comenzado a ser objeto de interés entre investigadores de todo el mundo. Las posibilidades de las narraciones transmedia están todavía en una fase inicial de desarrollo, tal como ocurre con su estudio. Frente a la ausencia de modelos en los que fundarse, los escasos intentos de hibridación con otras prácticas transitan caminos muy diversos que buscan su propio espacio de expresión, en el que los medios desplieguen todo su potencial significante y adopten las formas, reglas y diseños que la sociedad civil pueda emplear para canalizar sus discursos en el contexto digital de la modernidad líquida. Lo que parece obvio es que el viaje hacia la multimodalidad narrativa ha comenzado.

*El presente estudio ha sido financiado con la ayuda del Proyecto de Investigación de la convocatoria Universitat Jaume I-Bancaja, con el título "La crisis de lo real: la representación documental e informativa en el entorno de la crisis financiera global", código 111301.01/1, para el periodo 2014-17, bajo la dirección del Dr. Javier Marzal Felici

\section{Referencias}

Álvarez, J. (2007). Du jeu vidéo au serious game. Approches culturelle, pragmatique et formelle. Thèse Doctorale. Université Toulouse II.

Bogost, I. (2007). Persuasive Games. The expressive power of videogames. Cambridge, MIT Press.

Català, J. M. (2011): Reflujos de lo visible. La expansión post-fotográfica del documental. Adcomunica Revista de estrategias de Comunicación, $\mathrm{n}^{\circ} 2$, Castellón de la Plana: Asociación para el desarrollo de la comunicación.

Frasca, G. (2004). "Videogames of the oppressed. Critical thinking, Education, tolerance and other trivial issues". En HARRIGAN, WARDRIP (eds.) First Person. New Media as Story, Performance, and Game. London, MIT Press.

Gee, J. (2008): "Learning and game”, En SALEN, Kate (ed.) The ecology of games. Cambridge, MIT Press 
Genette, G. (1997). Paratext: Threshold of interpretation. Londres: Cambridge University Press.

Jenkins, H. (2003). Transmedia Storytelling. MIT Technology Review. January 2003.

Landow, G. (2005). Hipertexto 3.0: teoría crítica y nuevos medios en la era de la globalización. Barcelona: Paidós

Michael, D.; Chen, S. (2006). Serious games: educate, train and inform. Boston, Thomson Course Technology.

Ribas, J. I. (2000). Caracterització dels interactius multimedia de difusió cultural. Aproximació a un tractament específic, els "assaigos Interactius". Barcelona, Universitat Pompeu Fabra, Facultat de Comunicació.

Sicart, M. (2009). "Mundos y sistemas: entendiendo el diseño de gameplay ética", Revista Comunicación, $\mathrm{n}^{0} 7$.

Scolari, C. (2013). Narrativas Transmedia: donde todos los medios cuentan. Barcelona, Deusto ediciones. 